\title{
COMPUTER SYSTEM OF CONTROL AND ELIMINATION OF THE SPECIAL PROCESSES INSTABILITY
}

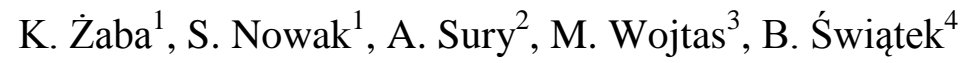

${ }^{1}$ Department of Non-Ferrous Metals, AGH University of Science and Technology, Cracow, Poland (rzyzaba@agh.edu.pl),

${ }^{2}$ Infoster Sp. z o.o., Cracow, Poland,

${ }^{3}$ Elsta Sp. z o.o, Wieliczka, Poland,

${ }^{4}$ Faculty of Electrical Engineering, Automatics, IT, Electronics, AGH University of Science and Technology, Cracow, Poland,

\begin{abstract}
The concept and example of inspection of special processes series, realised during production of critical aviation parts by the investment casting method is presented in the paper. The production cycle was described. Problems resulting from the lack of a possibility of application of the effective interoperational inspection and from the instability of process parameters were presented. The concept and structure of the dedicated expert system of collecting and analysing of data allowing the management of unit processes and their improvement were described. The methodology of constructing the science base on the grounds of archive data, necessary for the development of inference mechanisms assisting the decision taking processes was presented.
\end{abstract}

Keywords: Expert computer systems, Special processes, Critical parts for jet engines.

\section{INTODUCTION}

In case of special processes their regulation is possible only within the range of maintaining parameters of individual operations (unit processes) at the a priori assumed level. The set of these parameters creates "work point" of the process or technological line. However, there is no possibility of taking a decision on the semi-product state and eventual elimination it from the line. As a consequence costs are growing and a faulty product is made. The impossibility of elimination of a defected product lowers the yield.

The essence of special processes and fully controlled ones is presented in Figure 1-2. 
a)

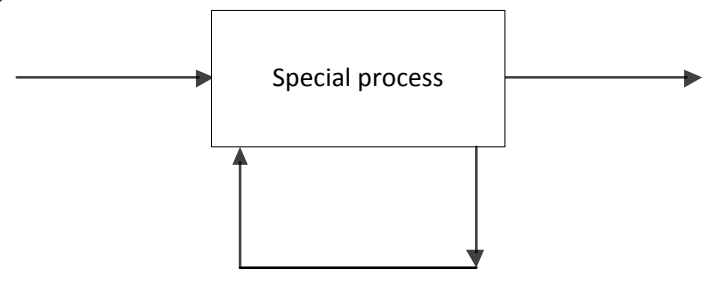

b)

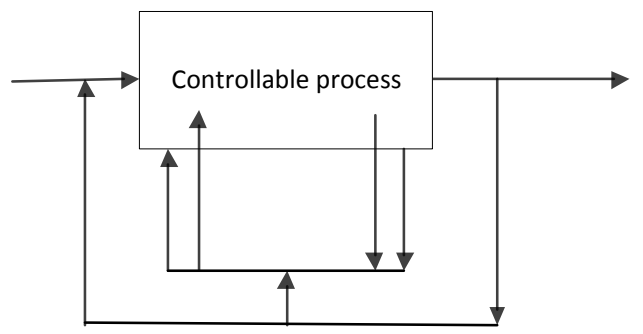

Figure 1. Schematic presentation of the special process (a) with its parameters controlled and the fully controlled process (b), where the control is done on the basis of the measured state of the semi-product and final product.

The case of complex, multi-operation processes is presented in Figure 2.

a)

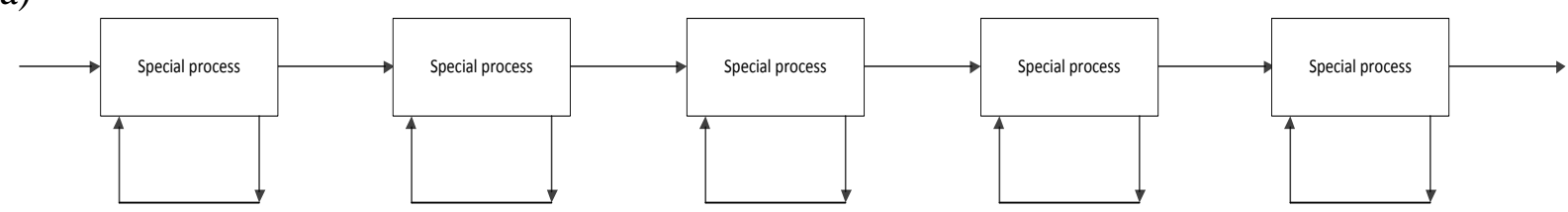

b)

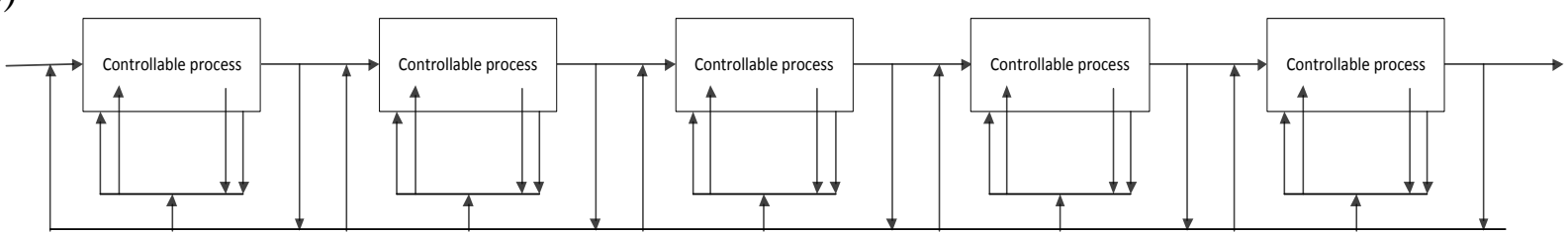

Figure 2. Schemes of multi-operation special processes (a) and fully controlled processes (b).

In case of a special process, at the allowable level of its standard variability (statistic), the only method of decreasing the risk of faulty production is the instability elimination, which means the elimination of extraordinary (failure) variability reasons.

In practice, in case of complex processes it is only possible provided that, they are effectively controlled, as much as possible without any human being participation who - by his very nature - is the source of errors, especially in situations when he has to take a decision.

It should be emphasised that all activities directed towards decreasing the defective production assessed by DPMO coefficient, initiated by economic reasons, will bring an additional effect. It is decreasing the risk of committing the II $^{\text {nd }}$ kind error, which means assessing the defected product as the one meeting the requirements. This is the more essential since the control requires the participation of men, admittedly widely supported but - in the end - undertaking subjective final decisions.

Special processes are e.g.: thermal treatment of metals and alloys, welding, electrochemical treatment, metallurgical processes and processes related to moulds production and casting.

In case of a thermal treatment an example of consequences of a process instability are internal defects of aluminium alloys plates. They occur after exceeding the upper limit temperature during heating for hyperquenching. The allowed temperature range of this 
process is very narrow. The plate surface after test-heating at the wrongly chosen temperature as well as the structure defects observed at the plates cross-section are presented in Figure 3.

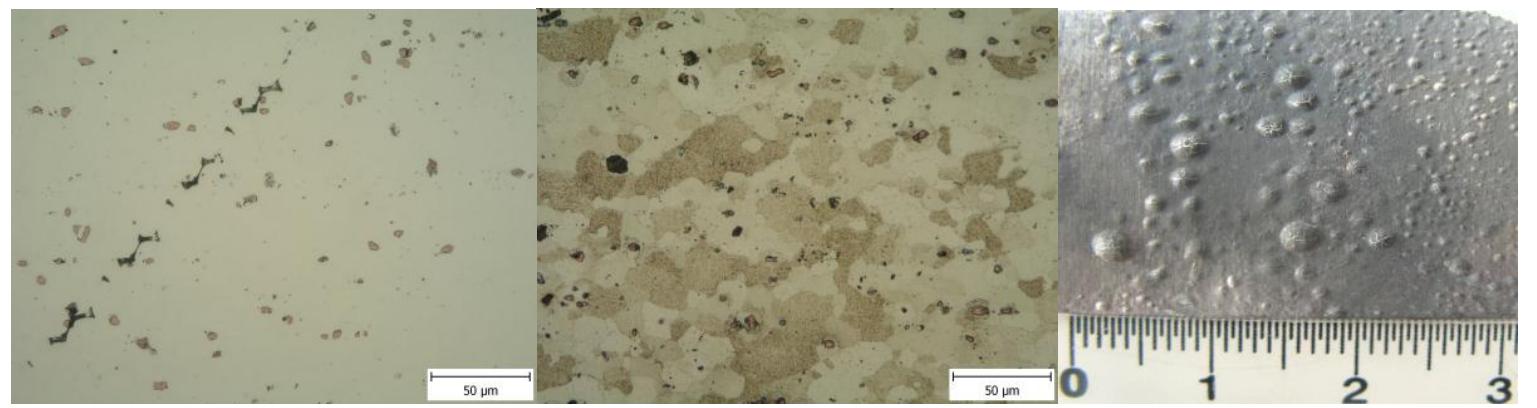

Figure 3. Plate surface and structure defects caused by instability of aluminium alloy heating.

Blowholes and cracks occurring in a weld are effects of the welding process instability. Defects of the weld in case of aluminium alloys welding by plasma method in the helium atmosphere are shown in Figure 4.

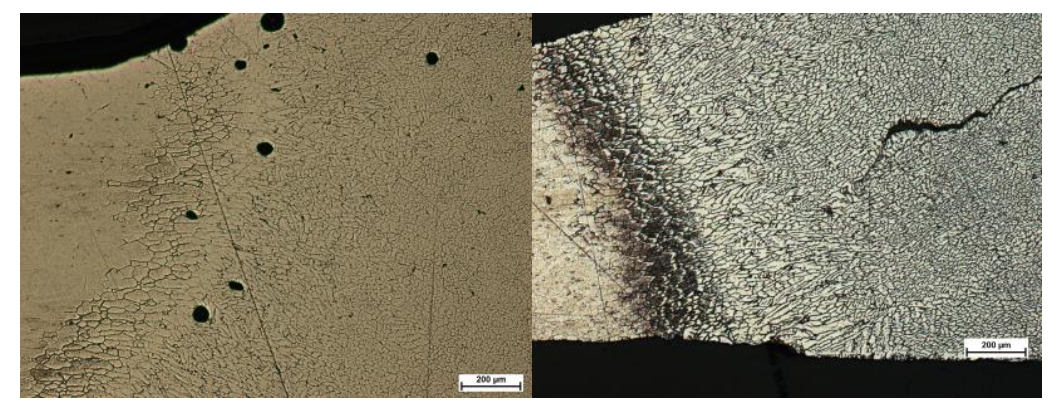

Figure 4. Blowholes and cracks in the weld as an effect of the welding process instability.

A characteristic series of special processes constitute the production system of making critical parts for jet engines. An element made of nickel alloy, inconel type, and its location in the engine is presented in Figure 5.

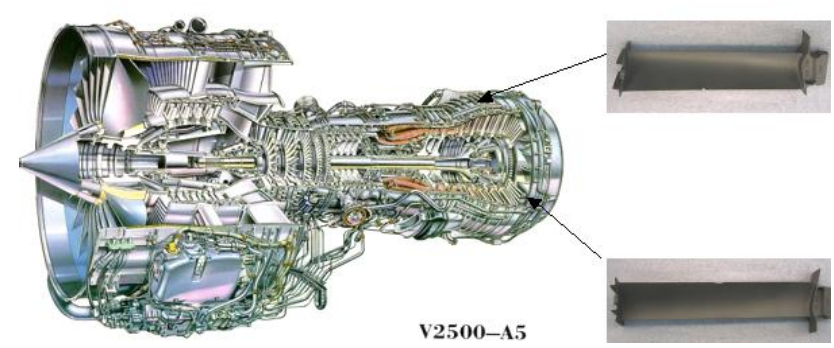

Figure 5. Example of the product and its location in the engine.

These parts are produced by the investment, vacuum casting into ceramic moulds. Moulds are made in a multi-operation process of placing ceramic coatings on wax patterns, wax melting, washing, drying and mould burning. After burning, moulds are warmed to an appropriately high temperature and poured with liquid metal in a vacuum. These processes and their series are special processes, which means that their result is estimated only when a complete hundred-percent multi-criteria control of the final product was made. 
The requirements to be met by products concern shape, dimensions, surface quality, grain size and mechanical properties, especially in high temperatures. Casting defects are unacceptable. Not satisfying any one of these requirements disqualifies the product. The final, hundred-percent inspection, adequately to requirements, encompasses: shape, dimensions, surface defects, slag inclusions, porosity, discontinuity, crystal structure defects. Tools for measuring length and angle, gauges, fluorescent methods, X-ray radiography, visual and microscopic observations are applied for the inspection. Wax pattern set and the ceramic mould before being poured with liquid metal is presented in Figure 6.

a)

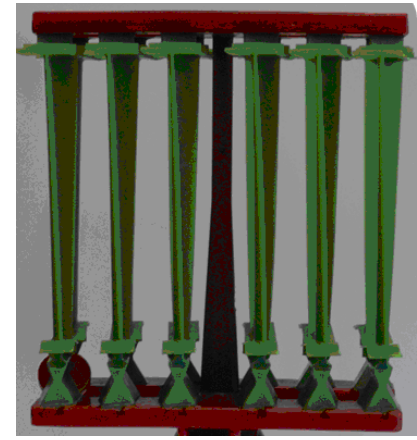

b)

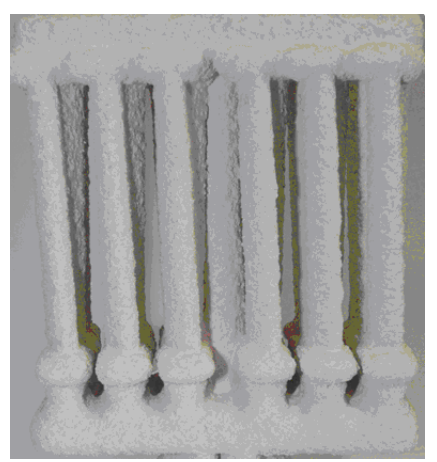

Figure 6. Wax pattern set (a) and ceramic mould before being poured with liquid metal (b).

Examples of cross-sections of a defective mould, obtained by the computer tomographic method, which indicates the structure state are presented in Figure 7.
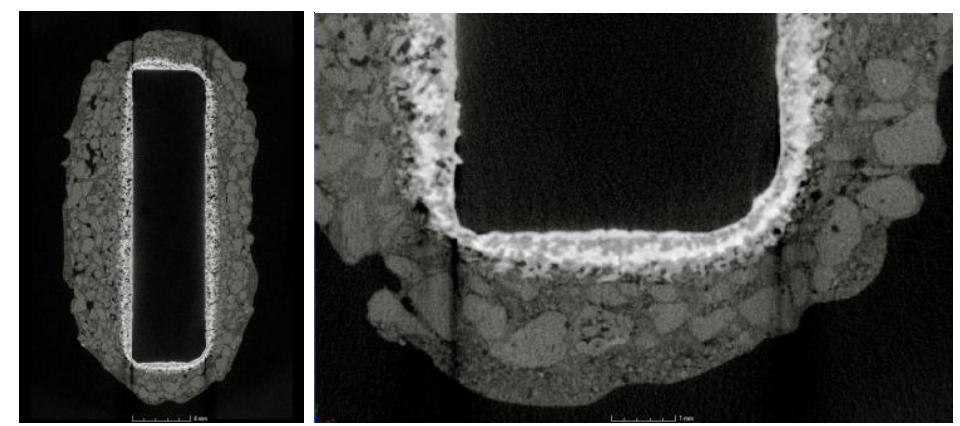

Figure 7. Photographs of the mould cross-section, obtained by the computer tomographic method.

\section{EXPERT INSPECTION SYSTEM, INSTABILITY ELIMINATION AND PROCESS IMPROVEMENTS}

The history of expert systems [1-4] is related to the development of scientific fields dealing with problems of smeared logic, neural networks, robotics, and process control. The scope of domains with which these systems are dealing is very broad - from chess play via pictures recognition for medical diagnostics. In the years 70 to 90 of the last century great hopes were pinned to systems using artificial intelligence and smeared logic methods. Unfortunately there is a stagnation in the development of these domains and it is difficult to expect any significant turning point. Excellent algorithms were developed used in individual applications, e.g. algorithms for sound pattern recognition, medical diagnostics, control, ect. 
however saying that this is already the 'artificial intelligence' is too much. Expert systems used in diagnostics and in control of complex technological processes apply methods of classic artificial intelligence however directed towards a close collaboration with a man, who is an expert in the given field and serve rather as assisting systems and supporting diagnostics.

Three criteria of dividing expert systems can be assumed. These are: interaction with a man, the way of realisation and the way of operation.

1.Interaction with a man:

- closed systems, it means undertaking the decision without any ingerence and inspection by a man, applied in controlling complex devices under conditions which are excluding or highly limiting a man's possibility,

- open systems (assisting) it means suggesting the solution helpful in undertaking the decision by a man. They present the solution of a certain problem but the user has to assess its value and decide whether he will accept or reject this solution.

- critical systems, it means performing the analysis of a certain problem and its solution and then commenting the proposed solution.

2. The way of realisation

- dedicated systems - created by the science engineer together with the computer expert with the full science data base defined at the system designing stage, and this science base can be supplemented during the system exploitation,

- skeletal systems - with an empty data base defined during the system exploitation in the training process.

3. The way of operation

- real time systems - processing incoming information e.g. from industrial automatic systems, they acquire real time expertise,

- analytical systems - acquired expertise is not required in exact time limits.

The remaining criteria of dividing the expert systems are related to their structure, computational methods, applied algorithms and the way of conclusions drawing. Such divisions are not accurate and the real systems - in the majority of cases - use various architectures and ways of concluding.

Each expert system is composed of three basic elements:

1. Science data base - set of information concerning the problem being the subject of the system operations. These information are divided into rules and facts, which after being processed by the system lead to the expertise development.

2. Inferring machine - set of algorithms (computer programs), which are to process information contained in the data base together with the real time information entering the system e.g. from measuring equipment of industrial automatics and from the system operator (employee).

3. User interface - used for communication between the system and user.

It was assumed for the need of the hereby study, that the expert system will be called the collection of programs and algorithms, which operation is directed towards the analysis of incoming data, diagnostics of eventual problems and assisting decision making processes, occurring in the production system control. The presented system can be classified as the dedicated system, (assisting) real time. Additional elements of this system are interfaces for 
exchanging data with devices of industrial automatics and with the remaining computer systems e.g. SAP, and also a special tracking system of production units.

Generally speaking the System presented in the paper is the MES class system extended for the dedicated expert functions. Functions of the typical MES class system:

- Process Management

- Performance Analysis

- Product Tracking and Genealogy

- Quality Management

- Data Collection/ Acquisition

- Document Control

- Resource Allocation \& Status

- Labour Management

- Maintenance Management

- Dispatching Production Units

- Operations/Detailed scheduling

One of the most important properties of the System is not only collecting, visualisation and data analysis for the needs of process managements but also helping operators of machines and devices, leading not only to the elimination of risks of erroneous decisions but also to indices of the OEE type. This can be achieved, among others, by plans presentations, operation scopes, fed answers in case of the necessity of undertaking corrective operations.

The hierarchical structure of the process management system together with the information flow from/to the controlled process is presented in Figure 8. The expert system integrates all levels of the automation pyramid and includes selected issues, which are not able to solve the standard systems.

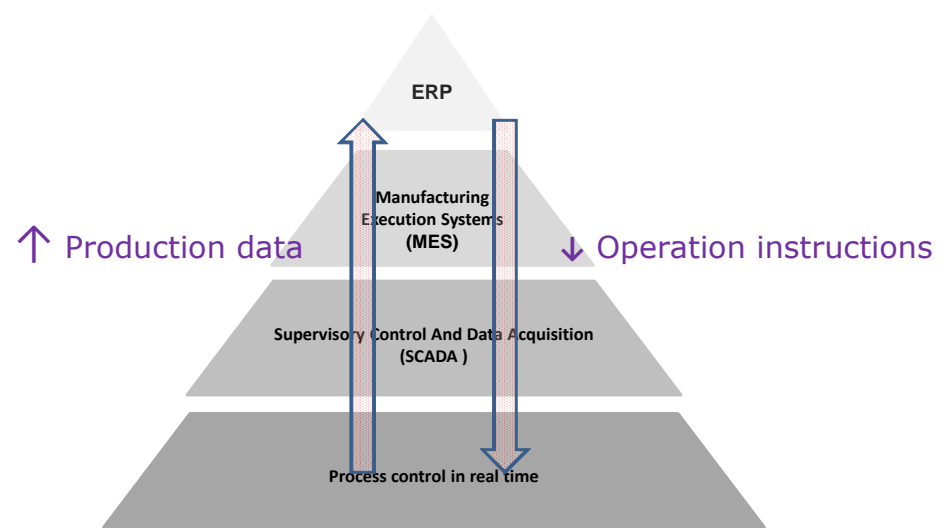

Figure 8. Hierarchical structure of the process management system.

The placement of the expert system among business systems in enterprises is shown in Figure 9. The dedicated expert system of real time supplements standard systems used in enterprises with tasks of supporting business decisions, advanced data analysis and supporting the controlled production process in order to maximize outputs and minimize losses. 


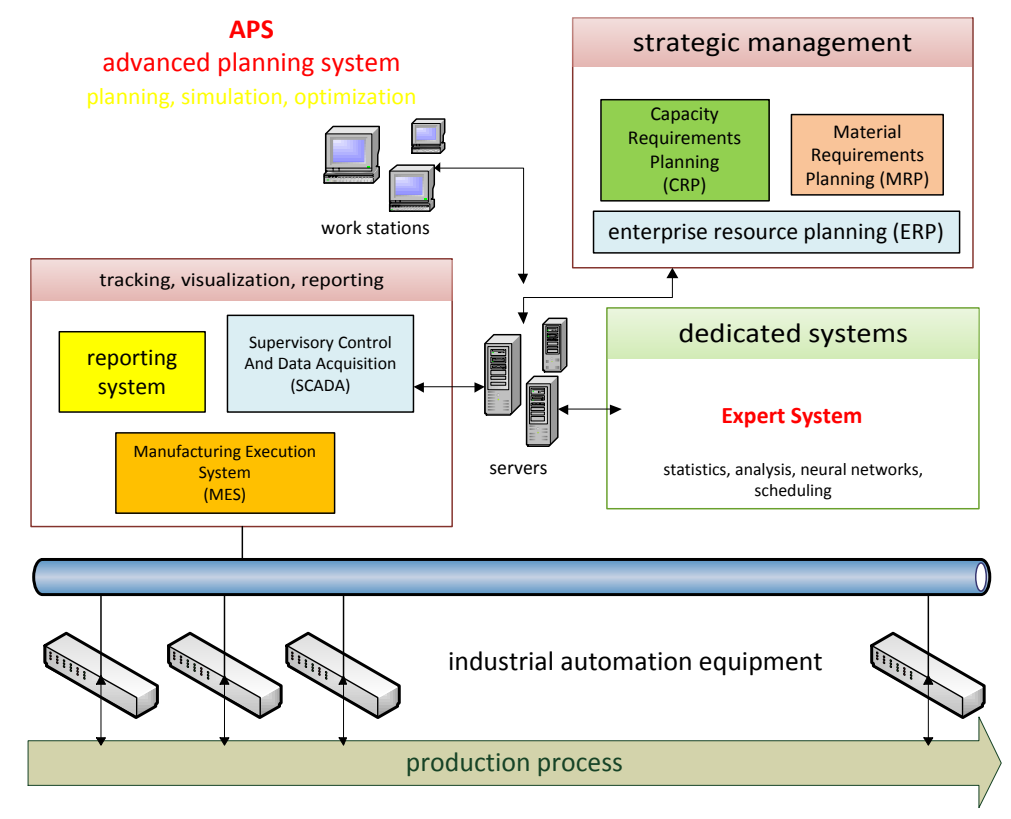

Figure 9. Structure of the expert system.

A block diagram of the production process control system, realised on the bases of the process data analysis is presented in Figure 10. The expert system is presented as an inference and analysis module with the science base represented as blocks of database and interface of the user integrated with the system management module.

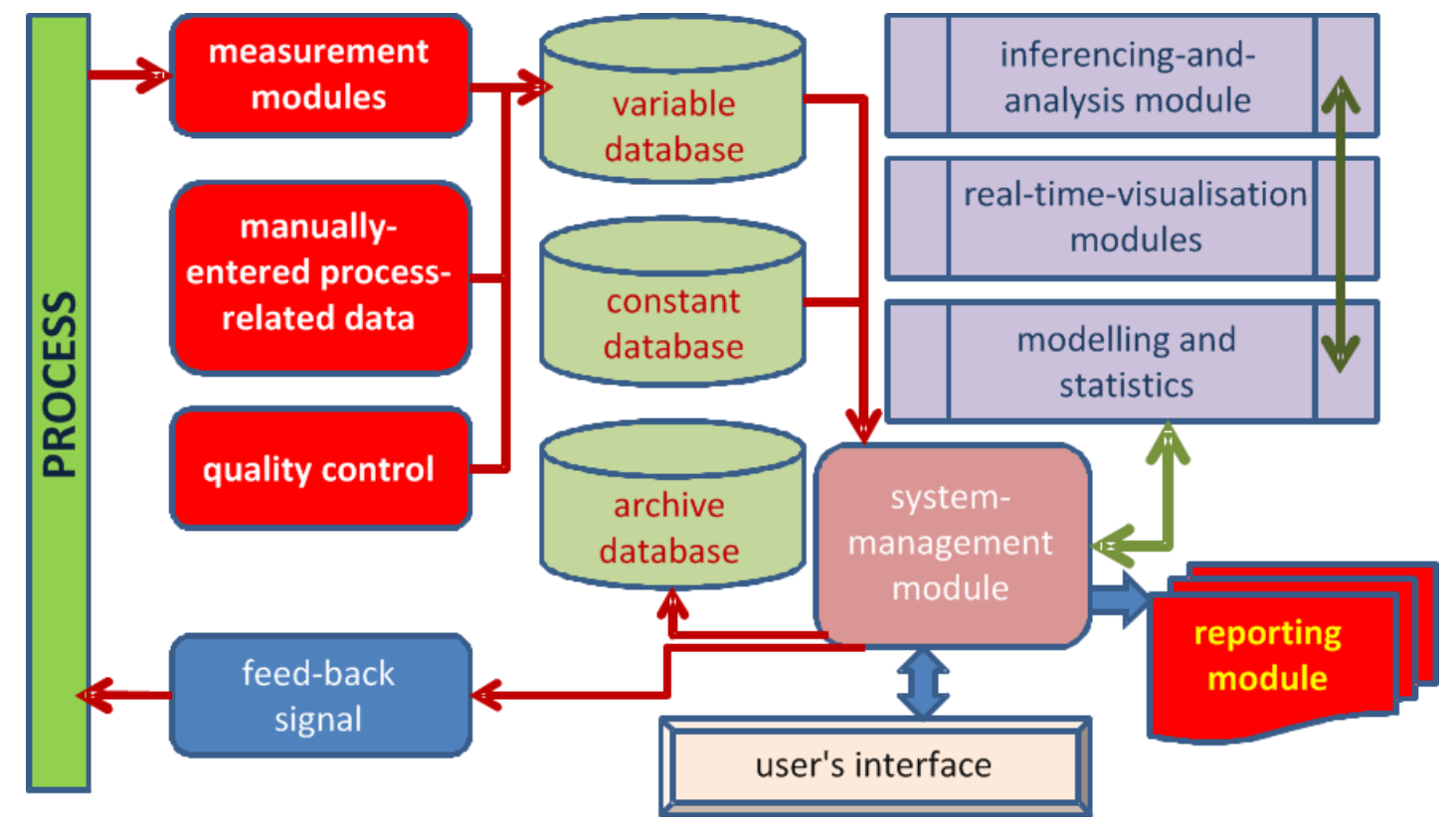

Figure 10. Block diagram of the production process control system.

\section{REALIZATION}

The example of the System realisation was directed to ensuring the stability of unit processes parameters, development of corrective signals, looking for reasons of defects and 
improvement of production processes of aviation parts obtained by the investment casting method. The pictorial diagram of the system is presented in Figure 11.

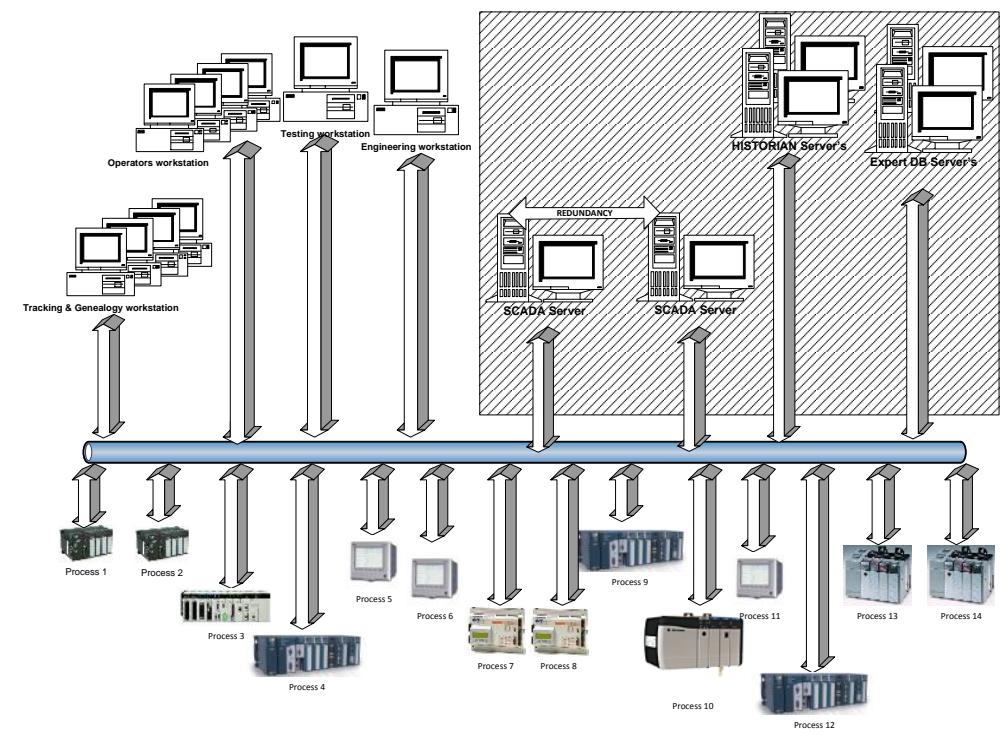

Figure 11. Pictorial diagram of the system.

The logic of the information flow in the system together with information protocols is shown in Figure 12.

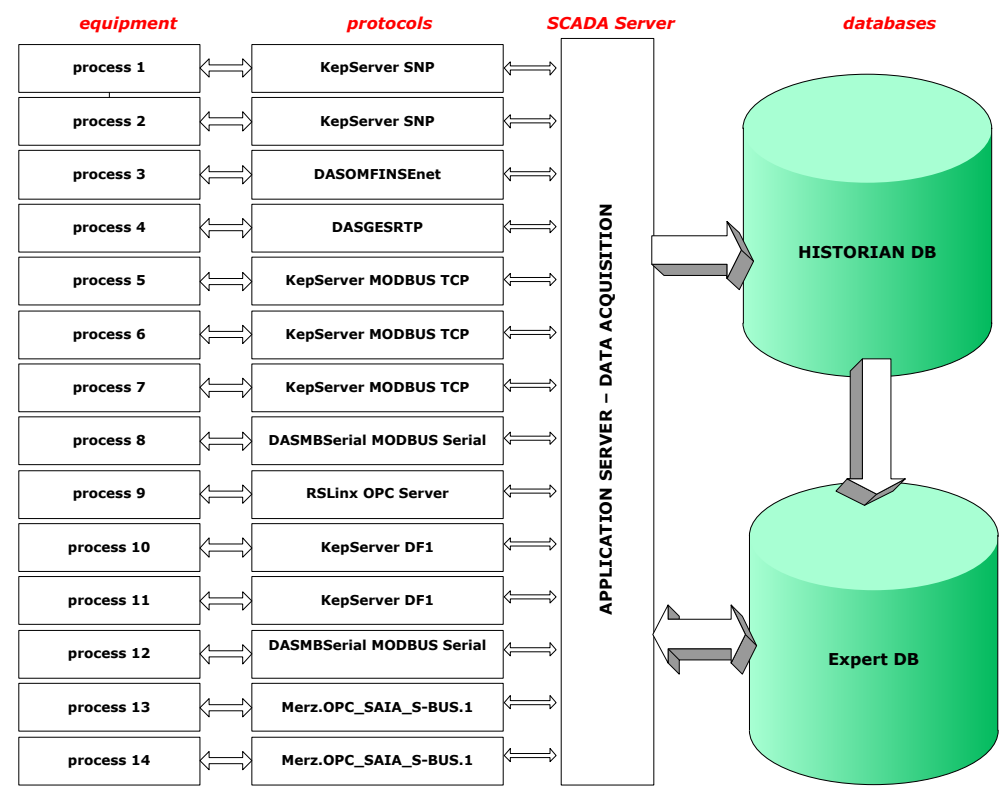

Figure 12. Logic of the information flow in the system.

Actualisations and modification in the system are performed with the proper safety standards (Figure 13). Because of that all actualization and modification operations are carried out first in the test environment and only after performing all tests they are implemented in the production system. 


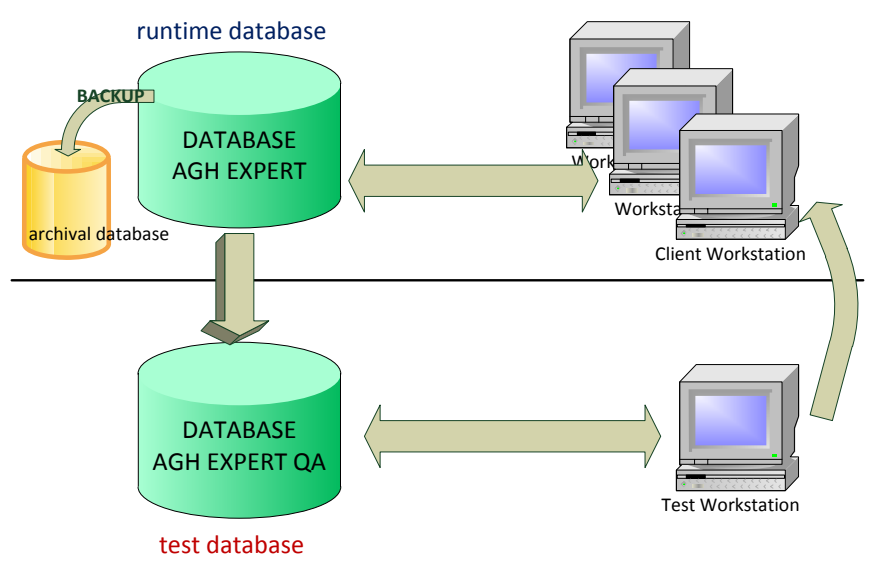

Figure 13. Actualisation and modification policy.

\section{EXAMPLES OF ANALYSES}

The results of various analyses performed by means of programs included in the Expert System are shown in Figures 14-31.

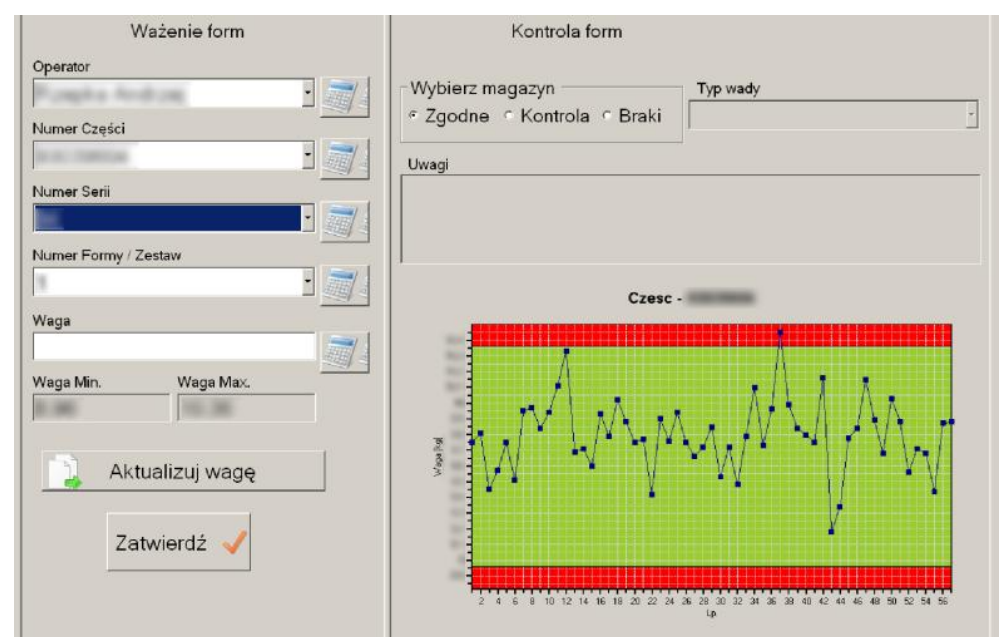

Figure 14. Example of the control card - form balance.

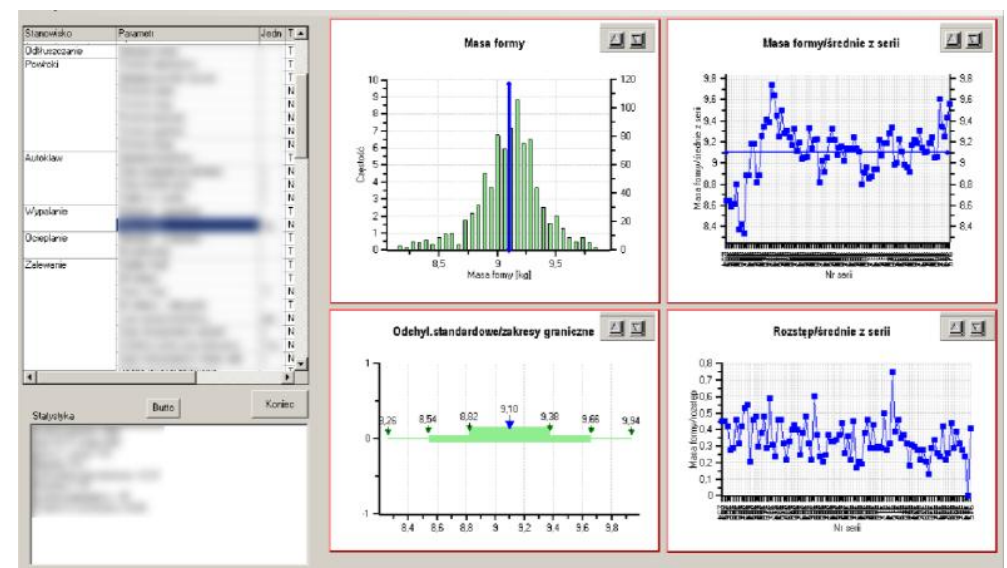

Figure 15. Examples of the statistical analysis results. 

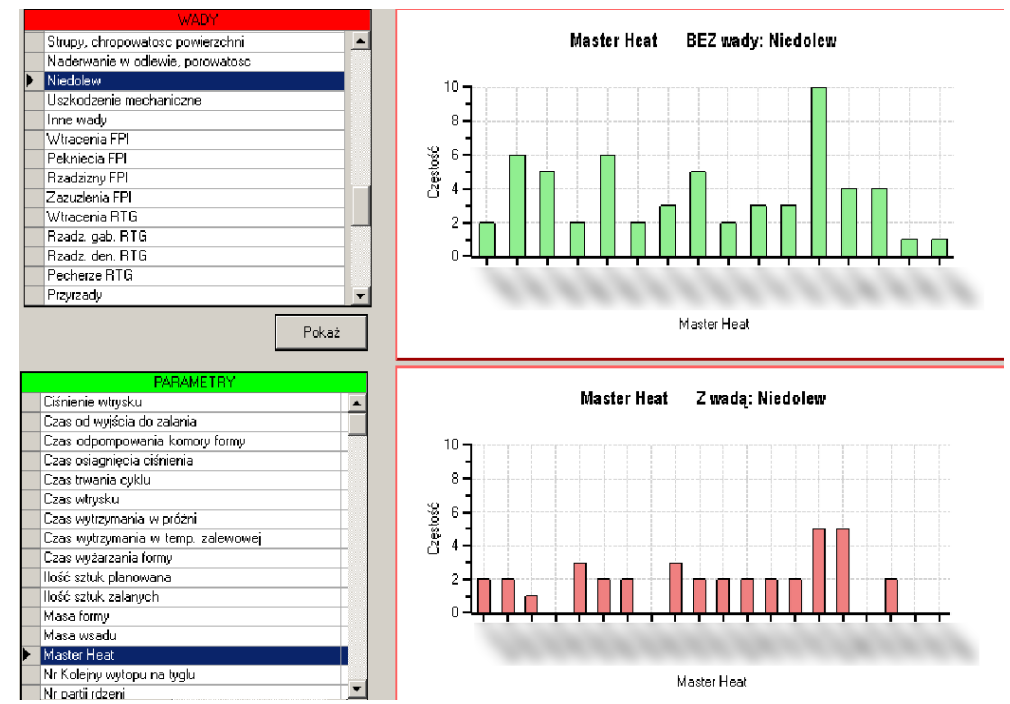

Figure 16. Example of the identification of defects and performance parameters.

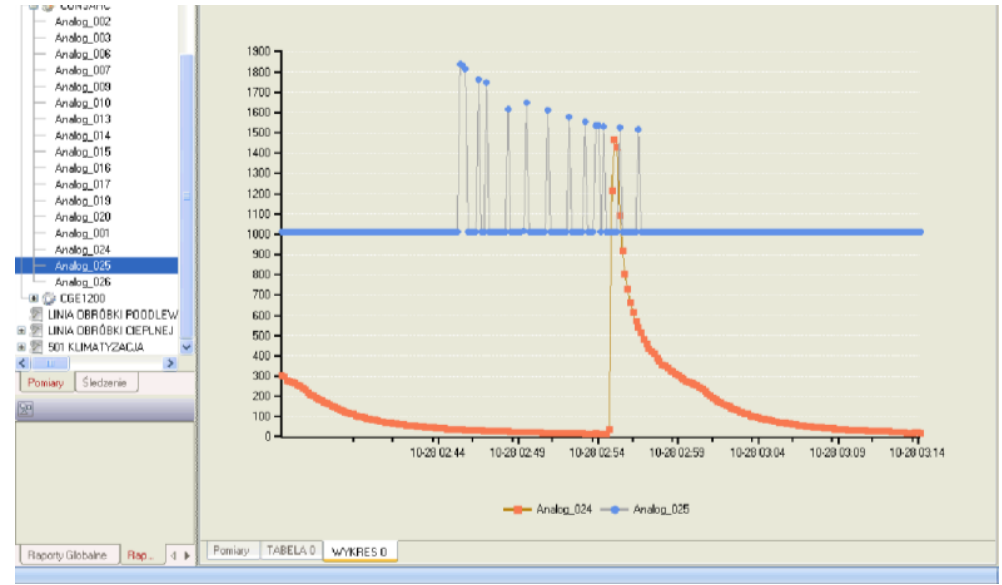

Figure 17. Alloy chemical composition - example of the analytical result.

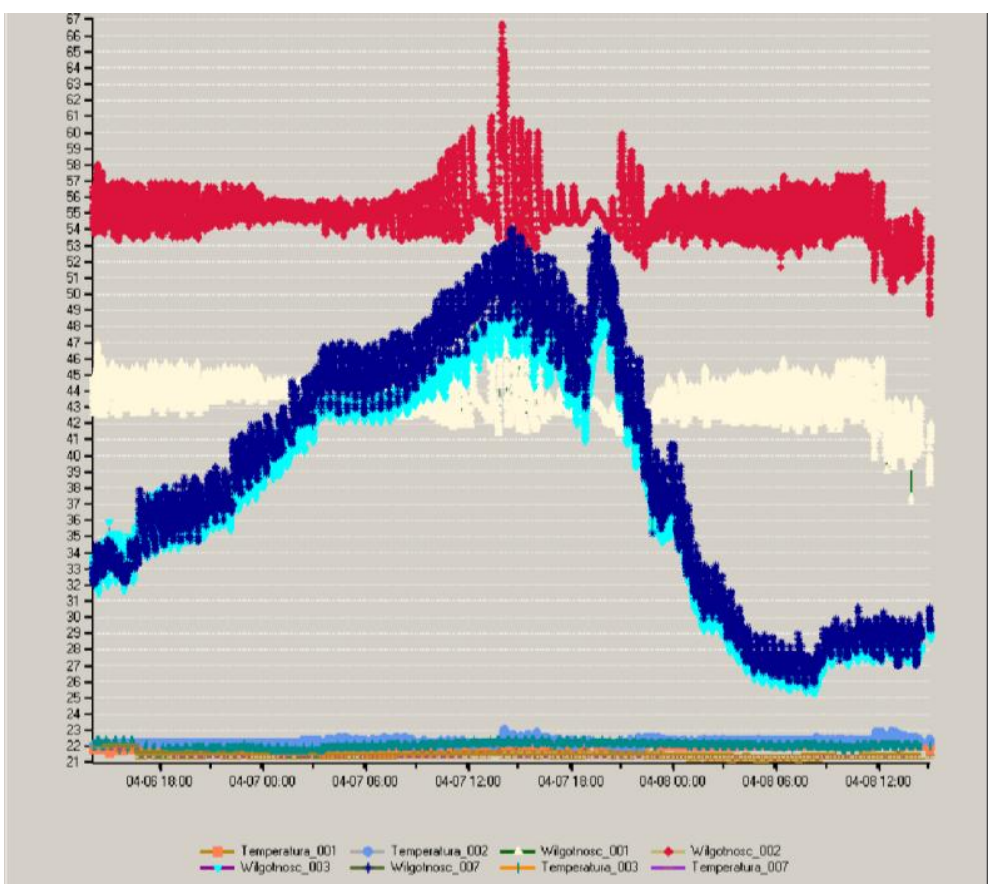

Figure 18. Out of control temperature and moisture content increase. 


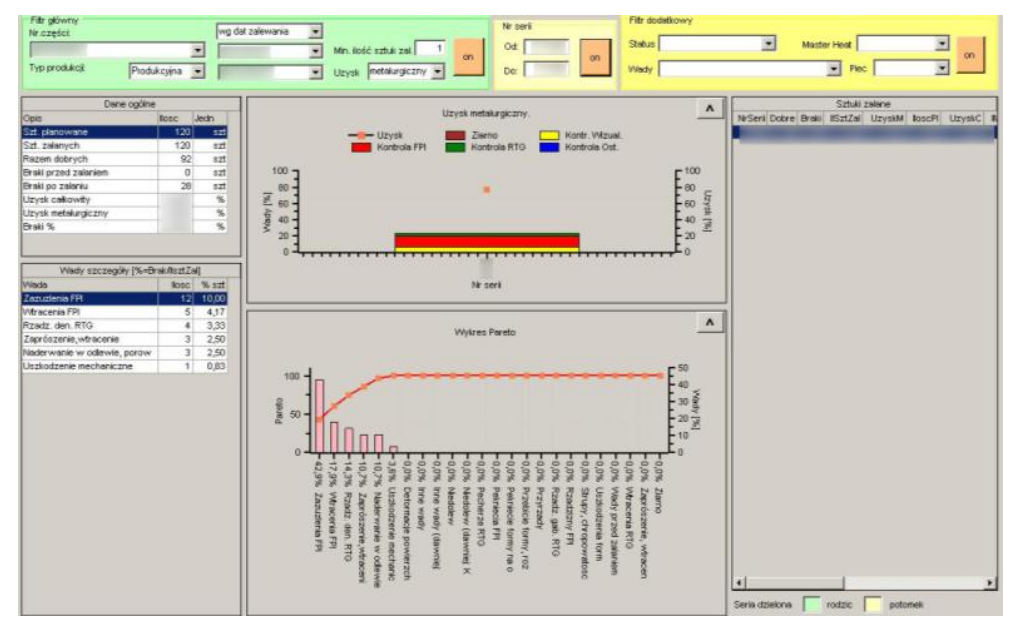

Figure 19. Detailed analysis of the given series.

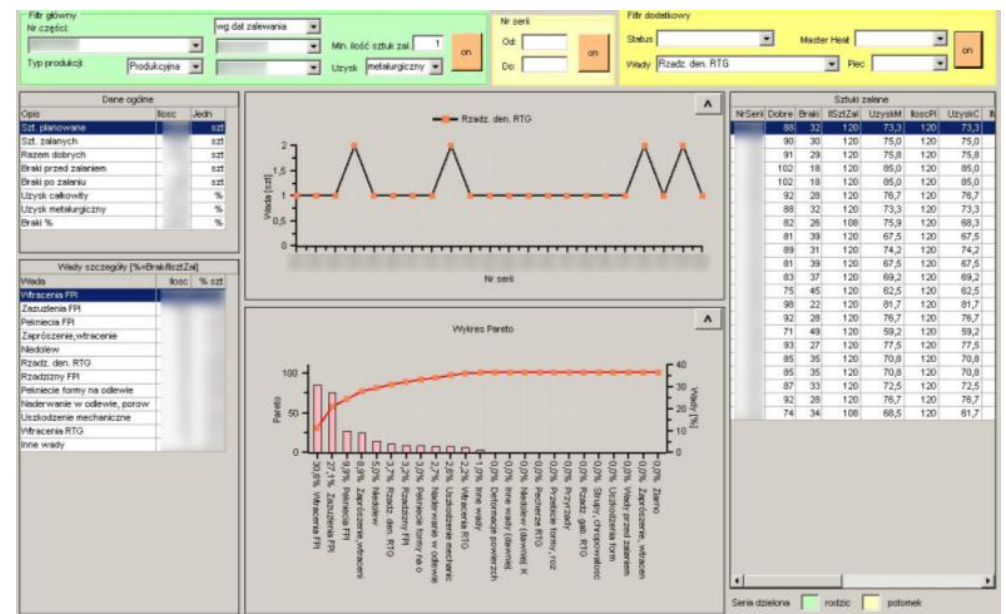

Figure 20. Analysis of a certain defect occurring in series.
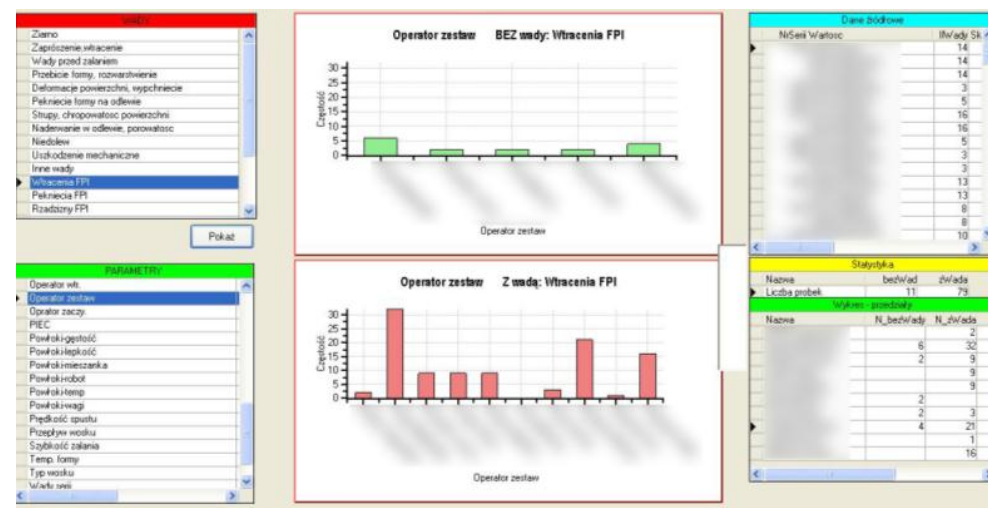

Figure 21. Analysis for the given part - inclusions FPI - Operator connecting the system. 


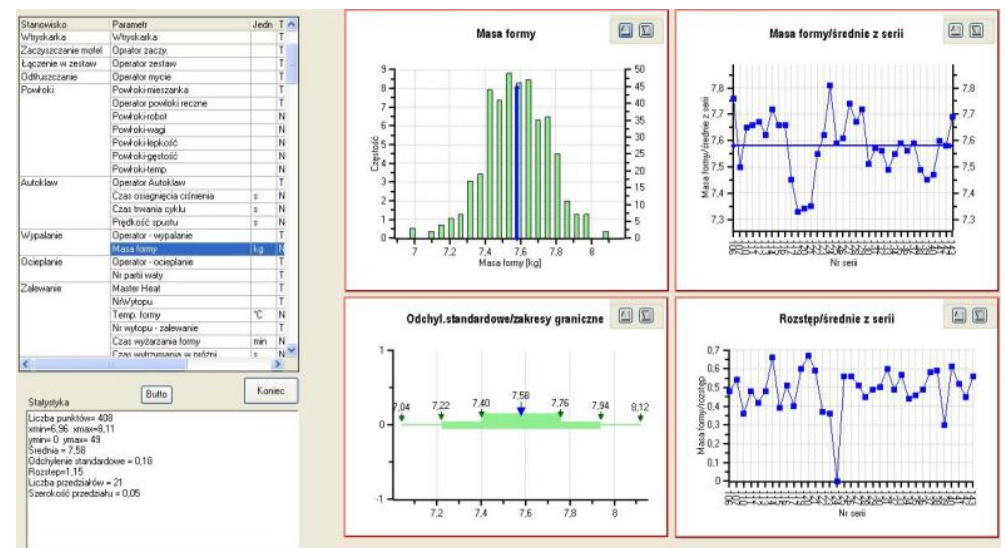

Figure 22. Scatter of moulds weight for the given part from the determined time.

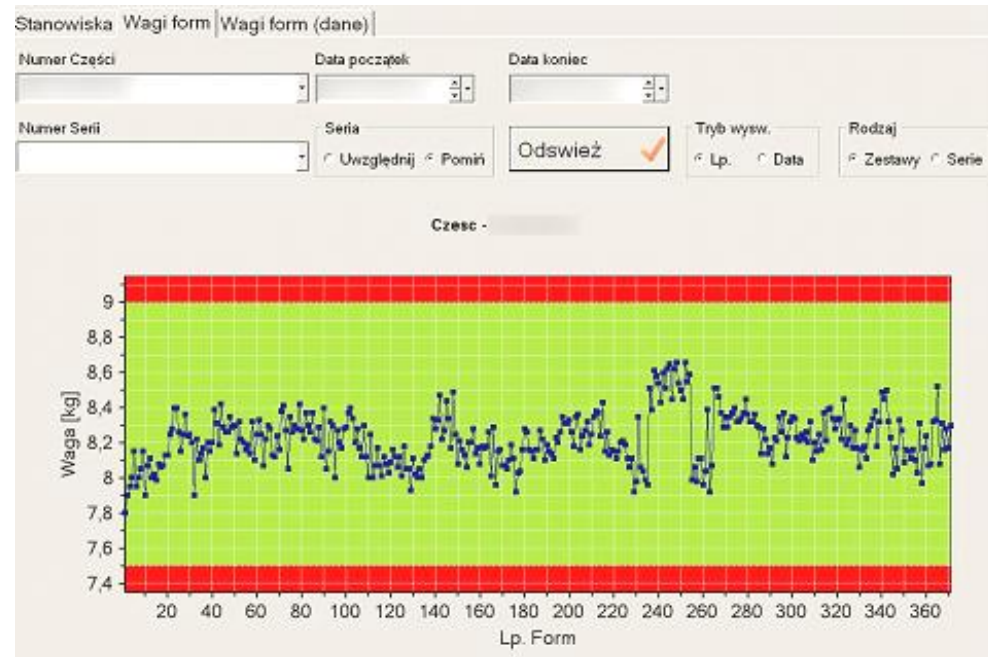

Figure 23. Current analysis of technological parameters.

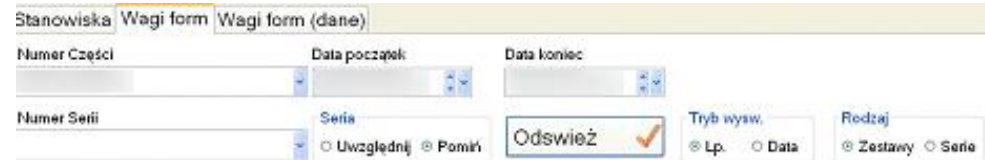

Czese

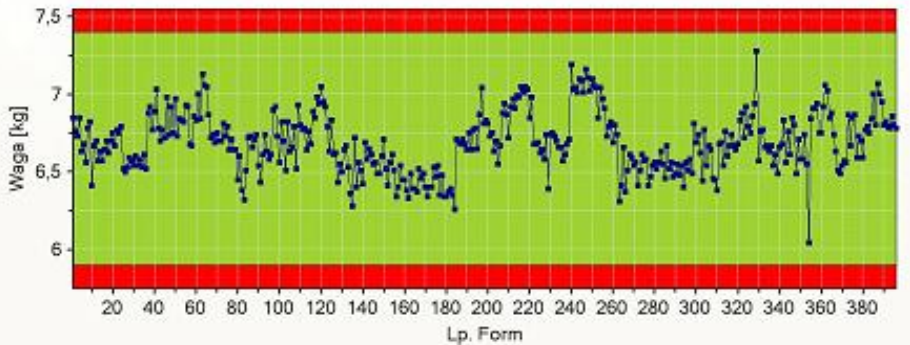

Figure 24. Weight control of ceramic moulds. 

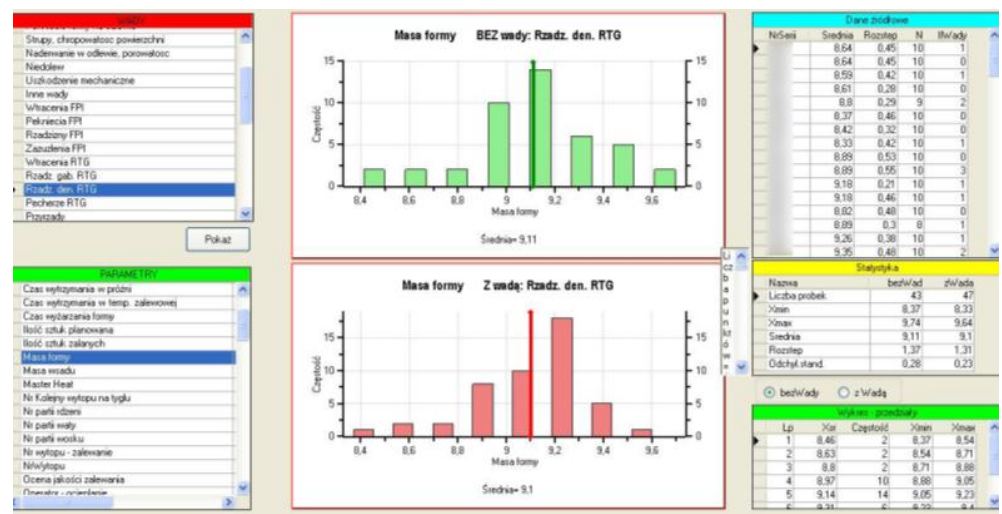

Figure 25. Analysis of the mould mass results.

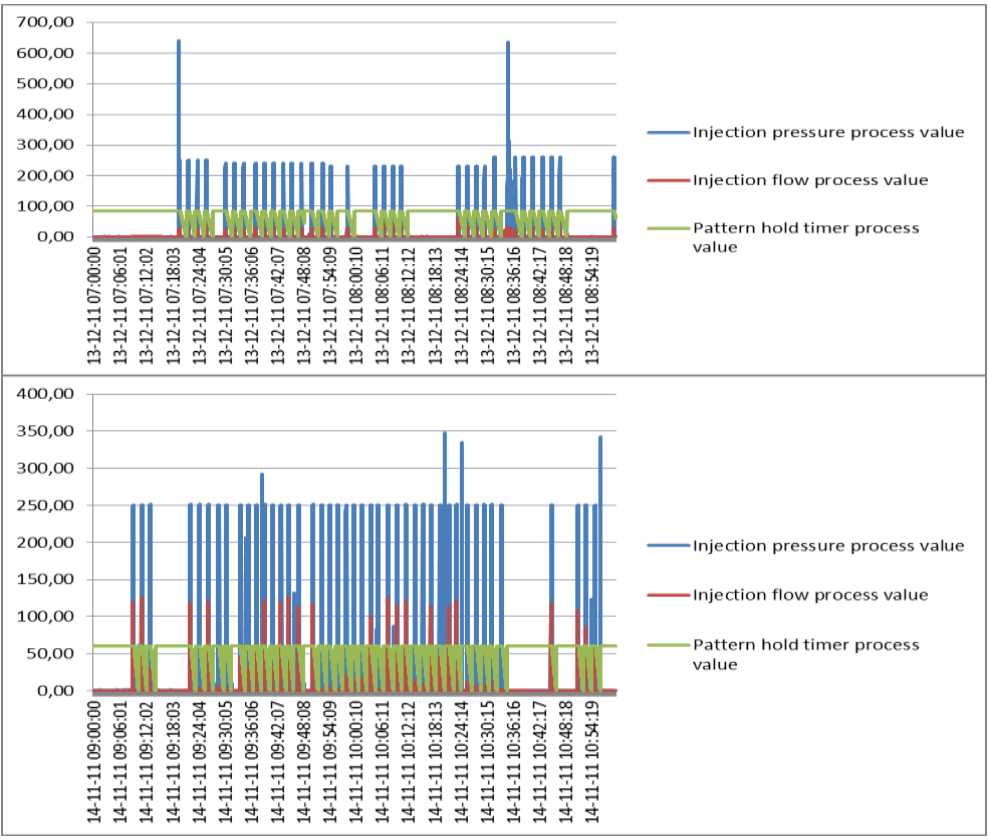

Figure 26. Injection parameters in the injection moulding machine - disturbances.

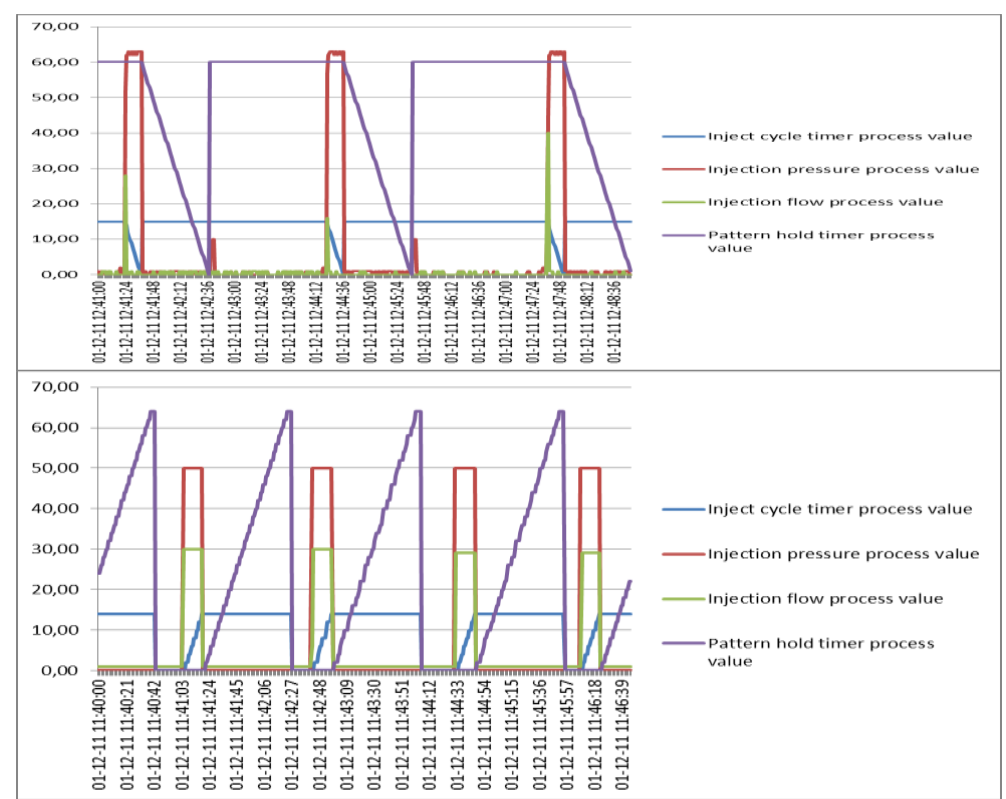

Figure 27. Injection parameters in the injection moulding machine - differences in operations of devices. 


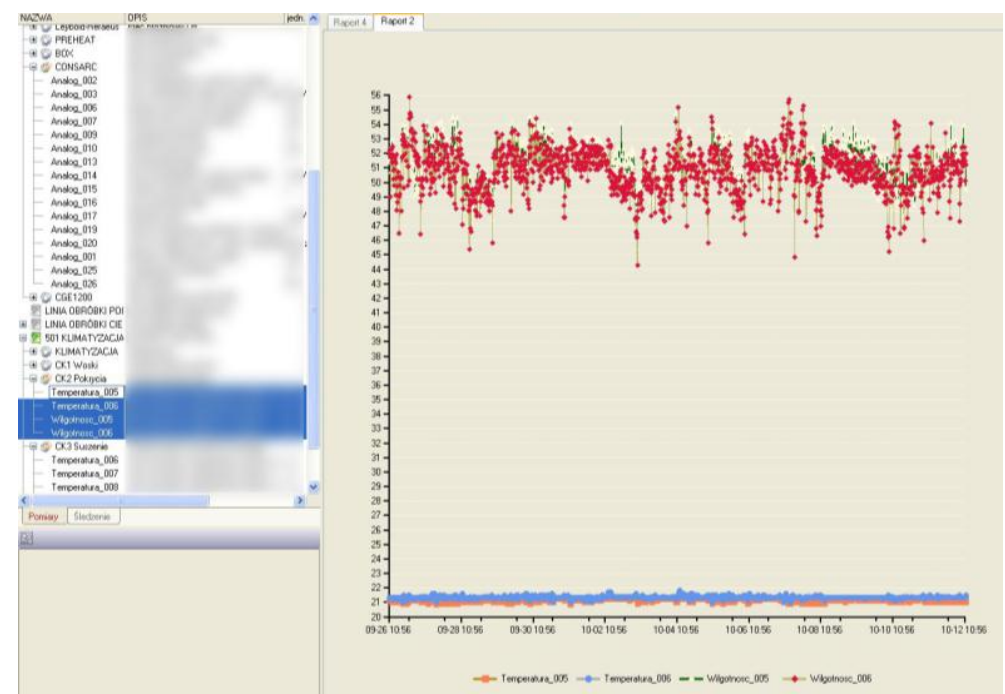

Figure 28. Temperature and moisture content at the stand for performing manual coatings.

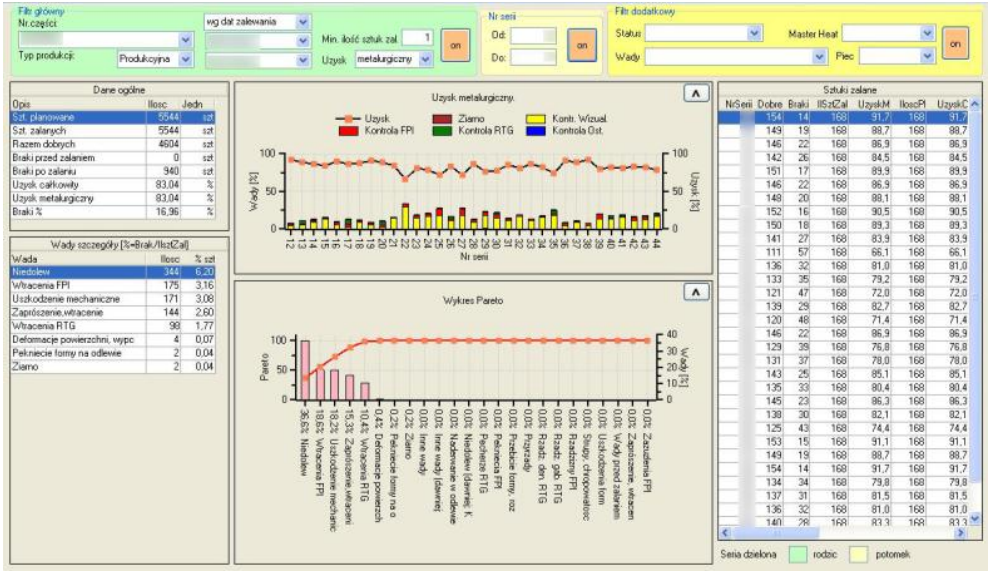

Figure 29. Metallurgical yield for the given part.
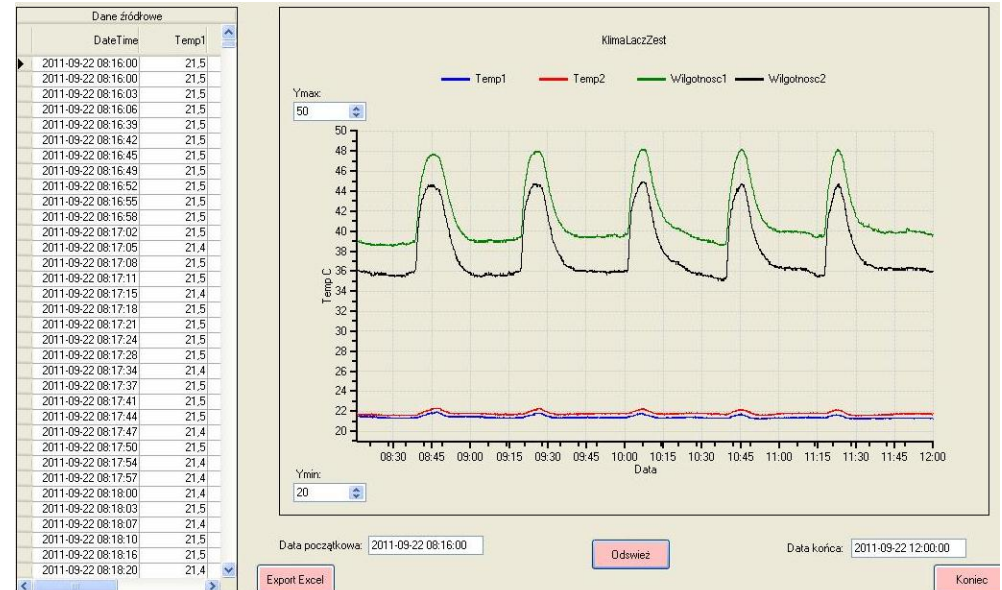

Figure 30. Temperature and moisture content diagrams during joining wax patterns. 


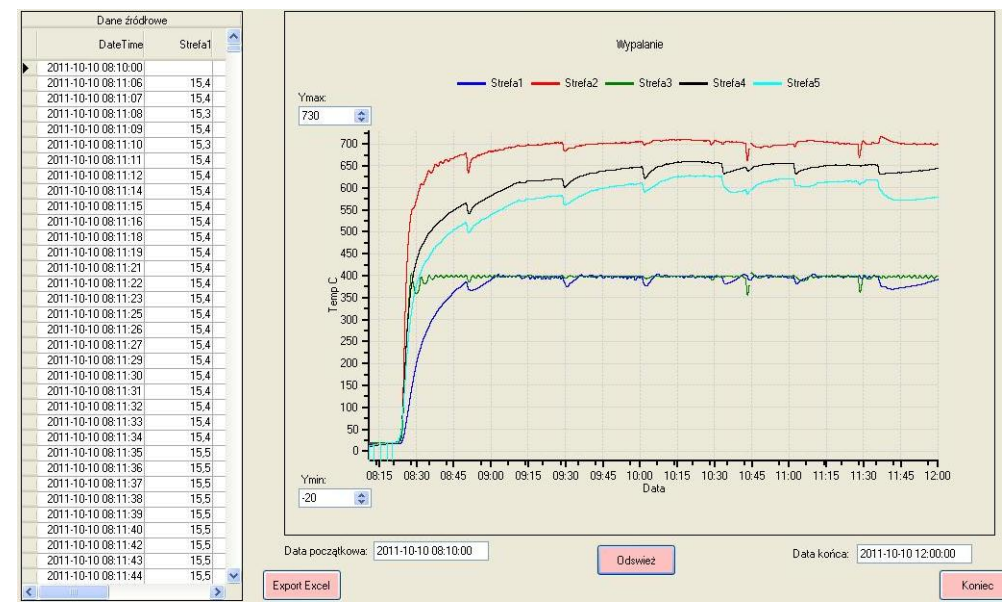

Figure 31. Temperature diagrams in each zone of the annealing furnace.

The described System realises classic SPC tasks by creating control cards and by development of warning signals (Figures 32-35).

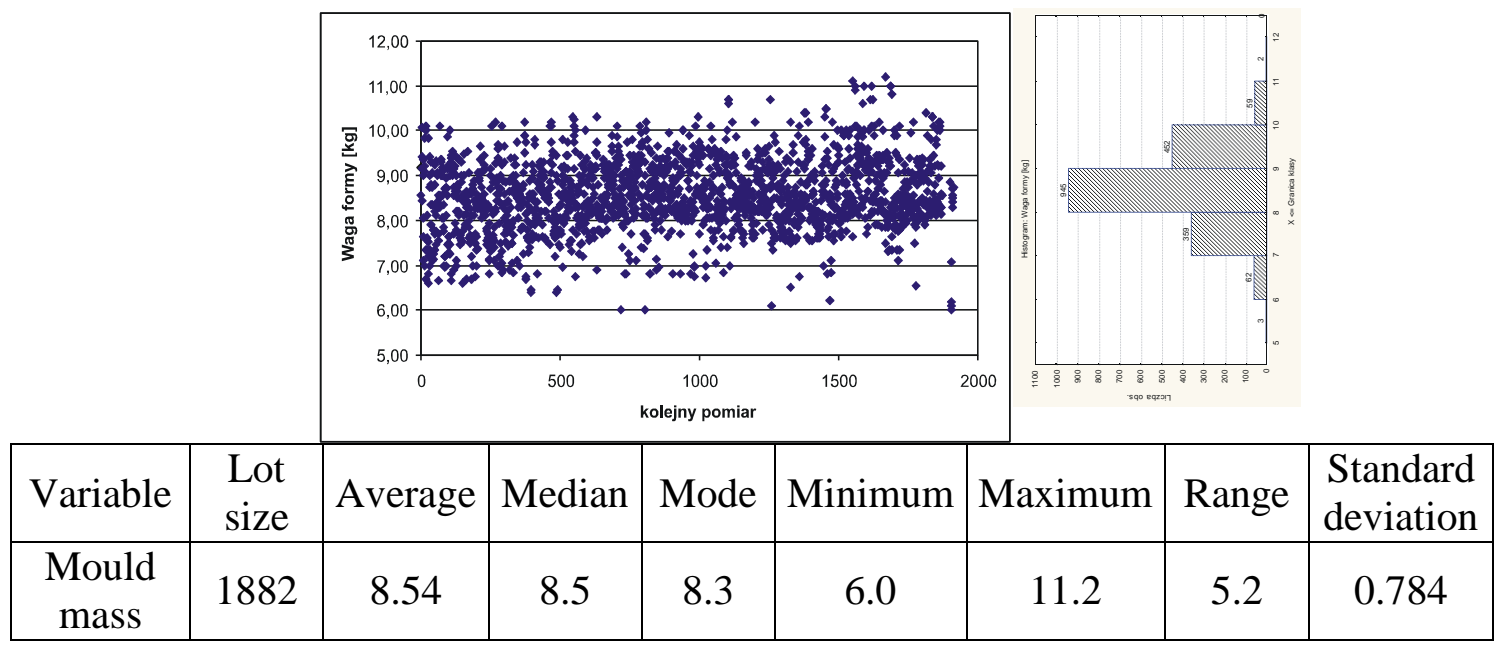

Figure 32. Variability - mould mass.

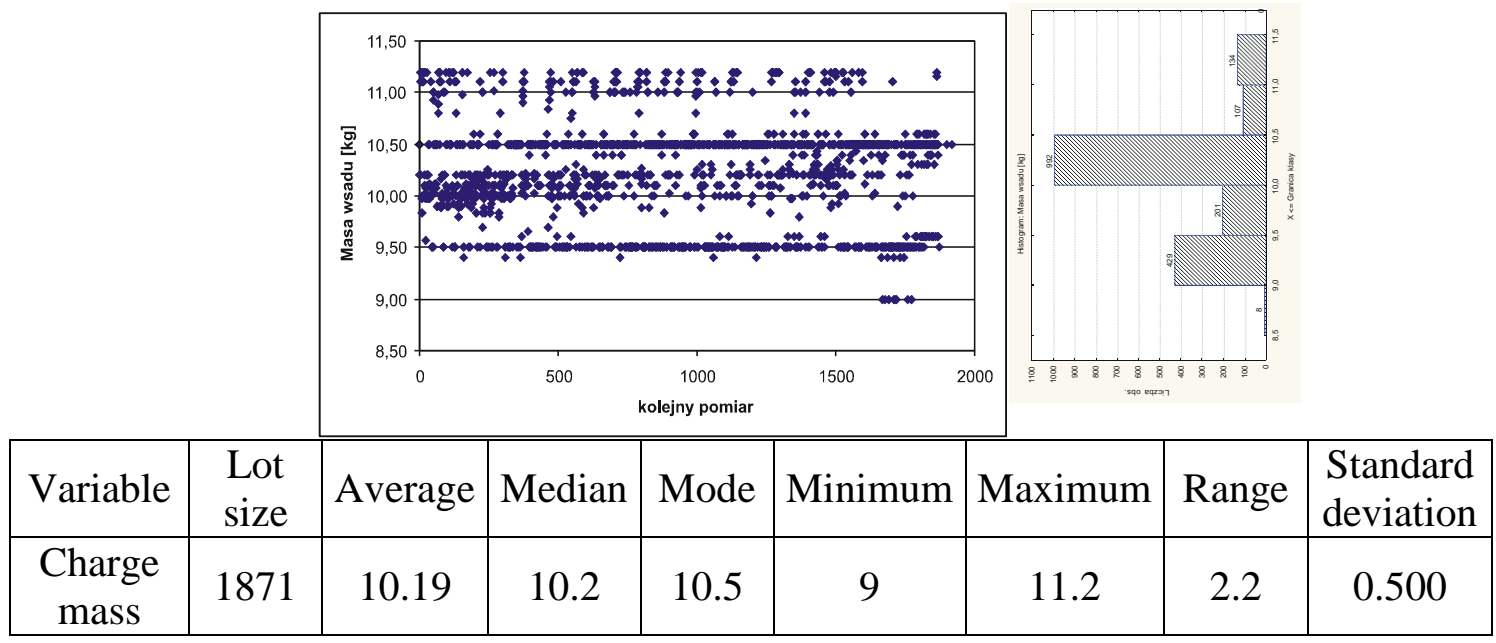

Figure 33. Variability - charge mass. 


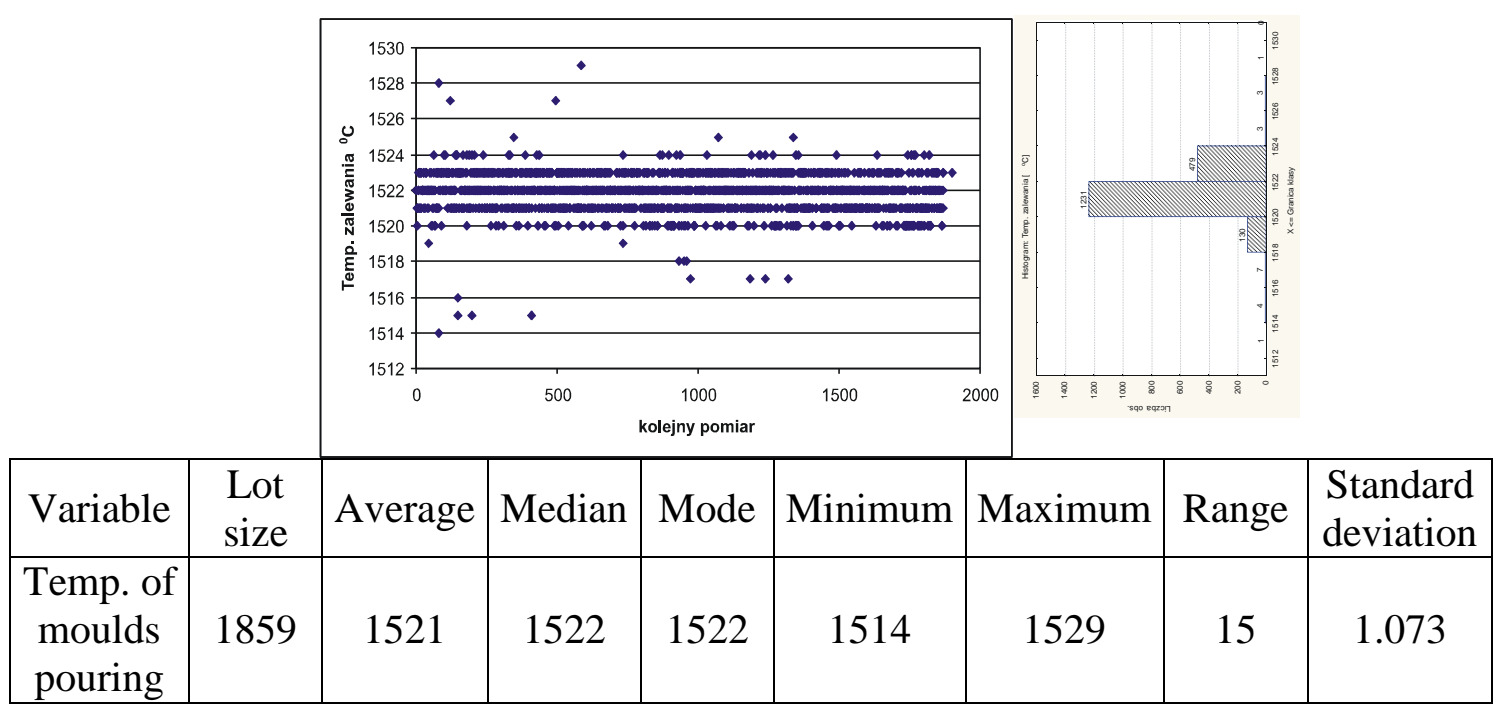

Figure 34. Variability - temperature of moulds pouring.

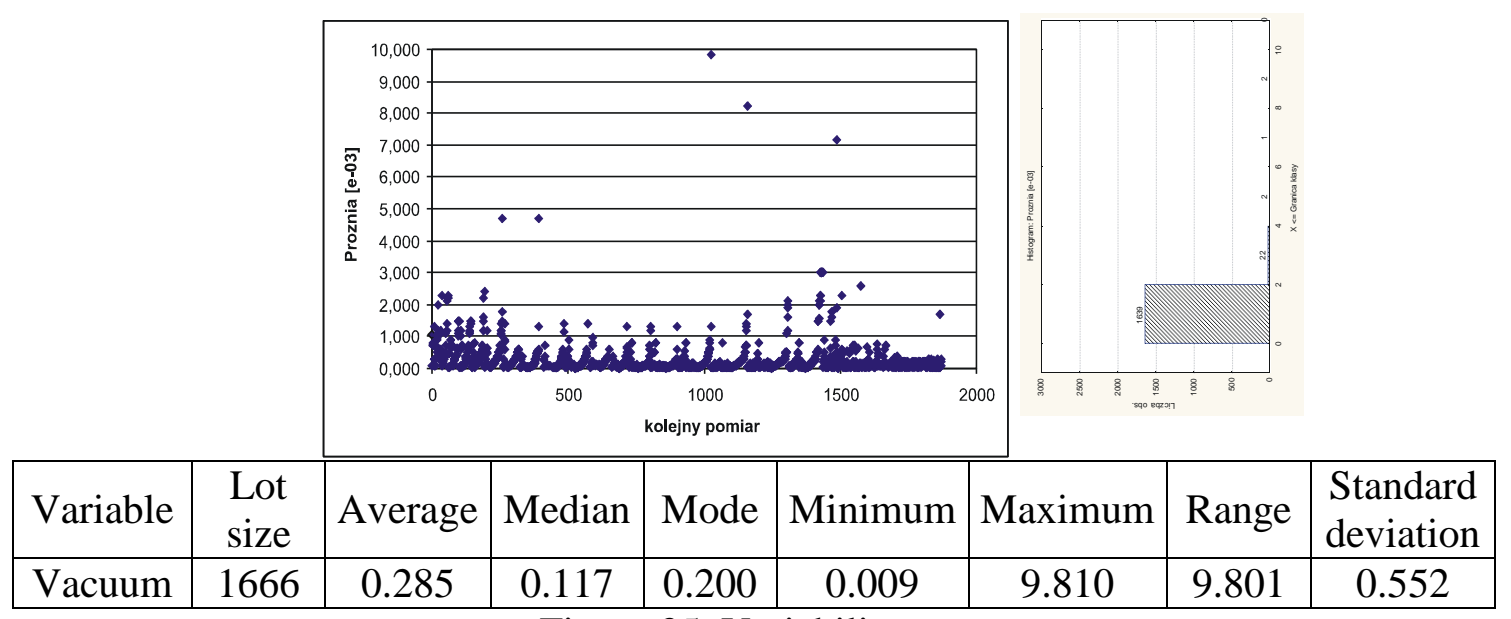

Figure 35. Variability - vacuum.

On the grounds of the historical data the statistic models of dependence between the selected parameters of semi-products or products and the unit processes parameters are formed. Examples of single-dimensional correlations can be found in Tables below. Examples of the regression analysis and multiple correlation are given in Figure 36. 


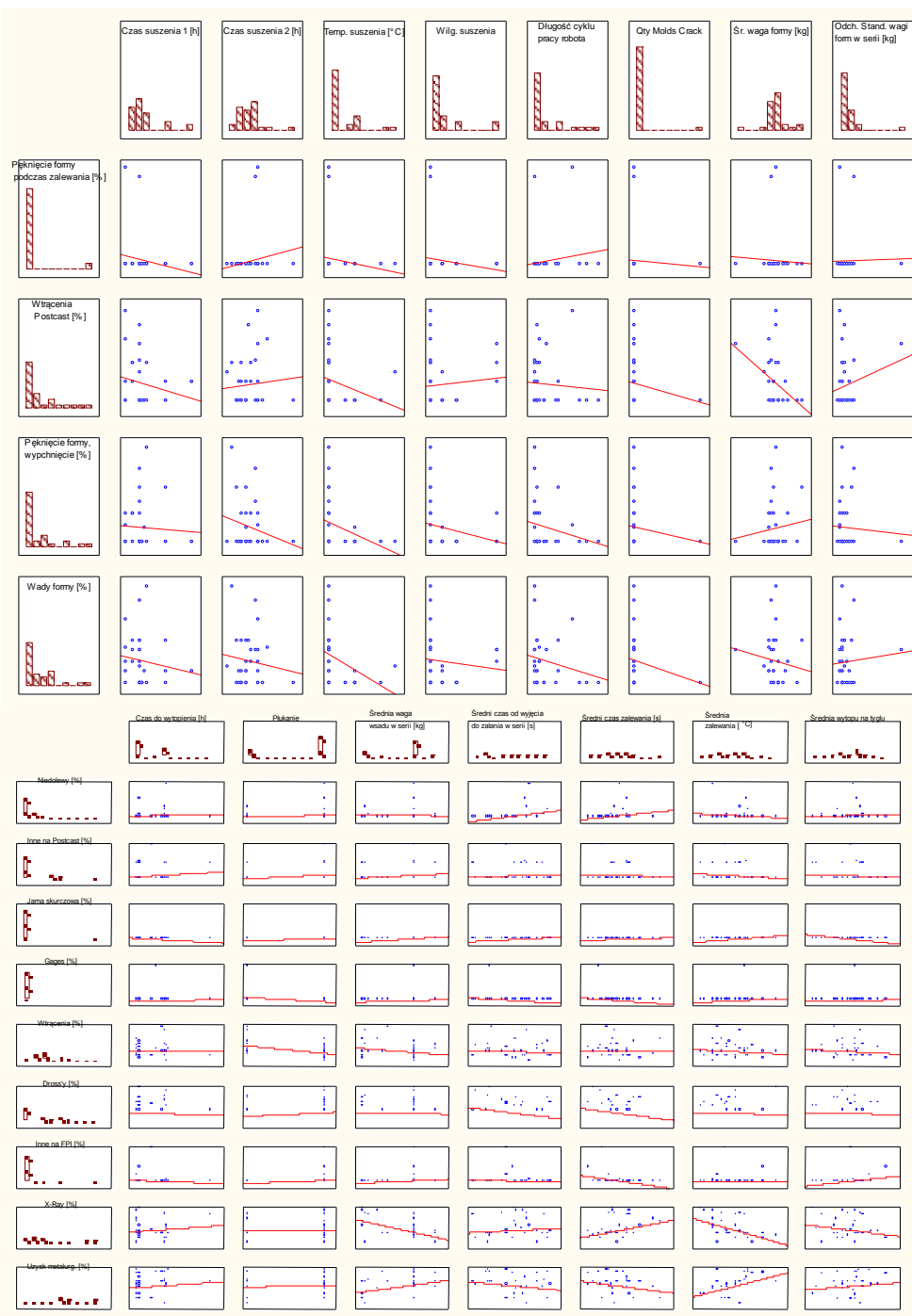

Figure 36. Mould and metal defect $=\mathrm{f}($ selected process variables $)$

\section{CONCLUSION}

The system presented in the paper realises 11 tasks:

1. Collecting of reliable data in the real time with the elimination of errors and delays introduced by a man - monitoring of the process and the results of inter-operational and final inspection.

2. Collecting feedback information from processes of further processing and exploitation data.

3. Analysis, data visualisation and assisting operational decisions with the usage of statistic SPC methods.

4. Modelling and simulation of processes directed towards the product quality forecasting.

5. Simulation of processes directed towards planning of the order book realisation and detailed scheduling.

6. Process control, directed towards parameter stabilizations, eliminating extraordinary variations and decreasing standard variations.

7. Control of the state and status of equipment, devices and measuring systems.

8. Determination of the key characteristics of processes. 
9. Analysis of archive data and drawing conclusions concerning the process improvements.

10. Development and transmitting automatic warning signals.

11. Building science base, on the grounds of archive data, necessary for creating mechanisms of drawing conclusions, which are supporting the decision processes.

However, it would be the best if - apart from the total control of processes - the possibility of inter-operational quality control would be assured since this will change the special process into the fully controllable one.

\section{REFERENCES}

[1] Korbicz J., Obuchowicz A., Uciński D.; „Sztuczne sieci neuronowe”, Warszawa, 1994.

[2] Russell S.J., Norvig P., „Artificial Intelligence A Modern Approach (3rd Edition)”, Prentice-Hall, 2009.

[3] Akerkar R., Sajja P., , Knowledge-Based Systems”, Jones and Bartlett Publishers, 2009.

[4] Giarratano J.C., P. Gary, Riley D., „, Expert Systems: Principles and Programming, (4rd Edition)", Thomson Press, 2004.

[5] Beynon-Davies P., „Inżynieria systemów informacyjnych”, Wydawnictwa NaukowoTechniczne, 1999. 